\title{
IIIOROSOOPY TOPAY
}

SEPTEMBER I 998

ISSUE \#१8-7

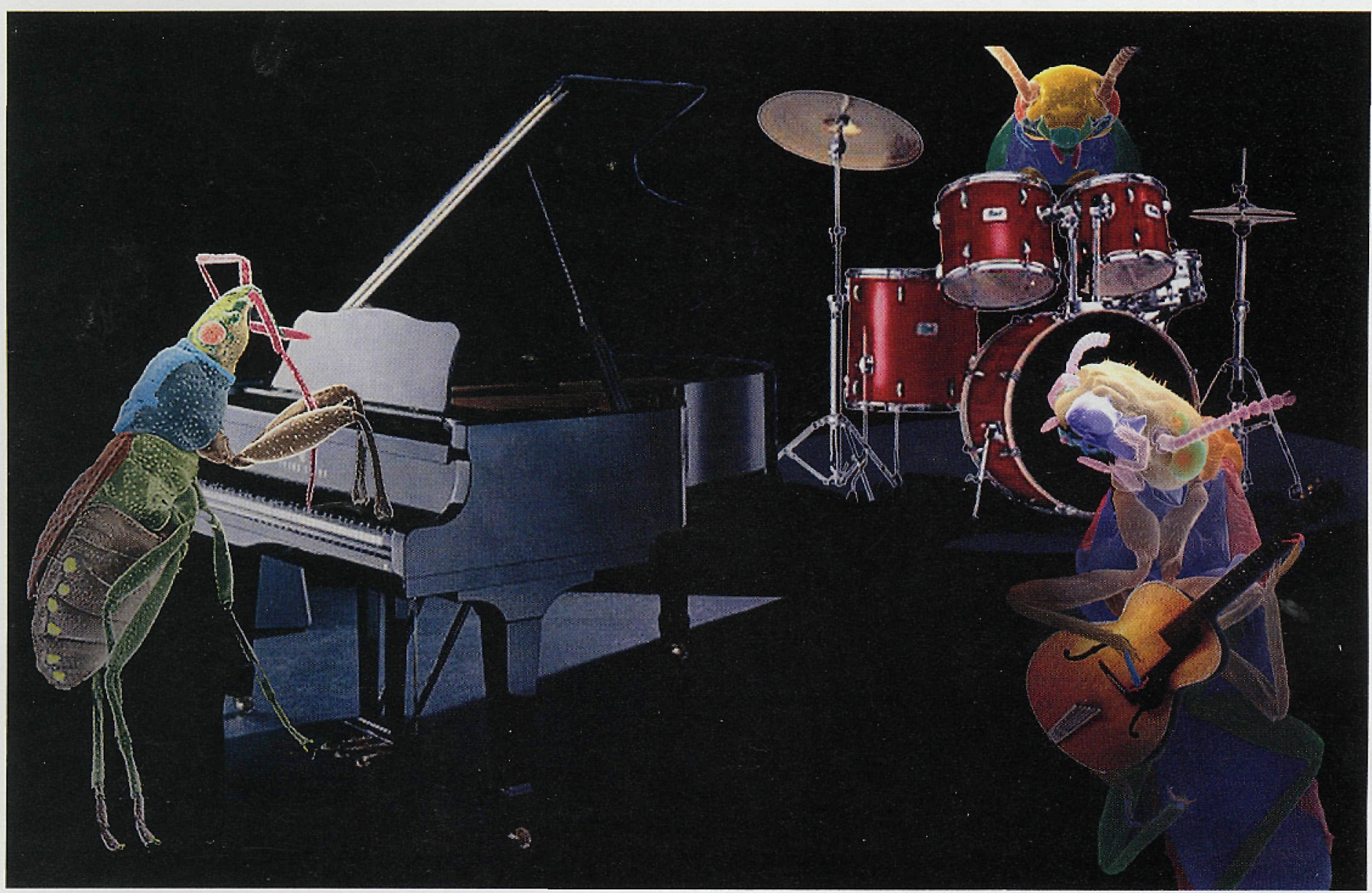




\section{Imaging Based on Elasticity \\ Stephen W. Carmichael, ${ }^{1}$ Mayo Clinic}

There are scores of microscopes that detect different properties of a specimen. Typically we image "visible" properties, but, for example, even the commonly-used atomic force microscope detects physical interactions rather than "visible" characteristics. Mostafa Fatemi and James Greenleaf have introduced the principle of imaging the elastic features of a specimen. ${ }^{2}$ This is done with sound waves, but we are not talking about just another acoustic microscope.

The method demonstrated by Fatemi and Greenleaf uses radiation force to image the acoustic response of a specimen to mechanical excitation. The mechanical excitation results from focusing two coaxial and confocal ultrasound beams of slightly different frequencies onto a selected region of the specimen. The arrangement is similar to having a monochromatic light source with a relatively large diameter, and fitting a light source of a slightly different color and smaller diameter at the center of the larger source, with both beams focusing at the same point in space (i.e., coaxial and confocal). The point at which the acoustic waves are focused creates an "interference" that produces sinusoidal modulation of the ultrasound energy density. This in turn creates an oscillatory force, effectively vibrating the selected region of the specimen. The resulting vibration of the object produces an "acoustic emission" (the authors point out that this term has different meanings in another context) that can be detected with a microphone (in this case, a hydrophone). The signal produced by the object varies with the elasticity at the focal point. By running the focal point of the two beams over the specimen in a raster pattern, a map related to the elastic properties of the specimen can be generated.
One model that was examined by this method was a glass bead (stiff) placed on a latex sheet (flexible). The $380 \mu \mathrm{m}$ diameter bead presented a large acoustic impedance discontinuity relative to the acoustically transparent latex sheet. This led to a high-contrast image of the bead within the sheet. In another test, iliac arteries from a young (uncalcified) human patient were compared to those from an old (calcified) patient. Calcifications within the arteries from the latter patient produced distinctive amplitude and phase values when compared to the uncalcified arteries. The acoustic spectrograms agreed with $X$-rays of the arteries, but gave an image of higher contrast and more details.

Fatemi and Greenleaf suggest that their method would be usefull for nondestructive testing of materials, and for biomedical imaging, extending the extent to which the physician's probing fingers can palpate stiffness. No doubt these are very' useful applications. But I would like to suggest that by increasing the frequency from the megahertz range (as used in their study) to the gigahert range, adjusting the detection range of the microphones as necessary, and narrowing the spot of convergence of the two acoustic beams (focal point), this principle could be the basis for a new type of microscope. The proof of concept is there, but scaling down to the microscopic world is nontrivial. The attenuation of the acoustic energy in water increases with the square of the frequency, so this physical problem (and others) would have to be dealt with. But consider how useful it would be to measure differences in elasticity within your specimens. Could the stiffness of one structure relative to the flexibility of another influence the interaction between the two structures? Think of the possibilities!

1. The author gratefully acknowledges Jim Greenleaf for technical advice and $g$ this article.

2.Fatemi, M. and J.F. Greenleaf. Ultrasound-stimulated vibro-acoustic spectography, Science 28:82-85, 1998

\section{Front Page Image \\ Second Prize - Just For Fun Micrograph Contest}

At the recent Microscopy \& Microanalysis " 98 Conference in Atlanta, Microscopy Today held a "For Fun" contest - with micrograph entries being a composite of two or more images, one of least being microscopical in nature. With fourteen entries and hundreds of "votes", Tina (Weatherby) Carvalho from the University of Hawaii won the second (and first) prize. Her description of this second prize image is:

Hawailan beetle on piano, termite on guitar and cockroach on drums. Images of insects taken with a Hitachi S-800, manipulated with Photoshop, and printed with a Fuji Pictography 4000

\section{mIOROSCOPY TODAY}

The ofjective of the publication, perhaps unlike many others, is to present articles and other material of interest and value to the working microscopist. With contributions from our readership, we attempt to cover all aspects of microscopy. The publication is mailed, ten times a year, at no charge to some

8,000 microscopists in the United States - all of which have requested subscriptions. Due to the current relatively low number of international readers, and resulting very high postage costs, we are forced to charge the following for international subscriptions ( 10 issues/year):

Canada, Mexico, Latin and South America. $\$ 40$ for one year, $\$ 70$ for two years other International. $\$ 55$ for one year, $\$ 95$ for two years

payment may be made by check, credit card or company purchase order.

\section{MIOROSOOPY TODAY}

PO Box 620122, Middleton, WI 53562

Tel.: (608)836-1970 - Fax: (608)836-1969 - eMail: MicroToday@aol.com - http://www.microscopy-today.com Copyright in 1998 by Today Enterprises. All rights reserved. 